\title{
RETRACTED ARTICLE: Measuring Routes Efficiency of Kolkata Bus Transport: A Modified DEA Approach
}

\author{
Asit Bandyopadhayay ${ }^{1}\left[\right.$ Ashim Banerjee $^{2}$. \\ Naseem Abidi ${ }^{1}$
}

Received: 2 March 2016 / Revised: 7 March 2016 / Accepted: 8 March 2016 /

Published online: 22 March 2016

(C) Springer-Verlag Berlin Heidelberg 2016

This article is hereby retracted by the authors as a result of double submission. The authors would like to apologize to the Editors and readers.

The online version of this article contains the full text of the retracted article as electronic supplementary material.

Electronic supplementary material The online version of this article (doi:10.1007/s40745-016-0074-z) contains supplementary material, which is available to authorized users.

$凶$ Asit Bandyopadhayay

dr.asitb@gmail.com

Ashim Banerjee

ashim.sripur@gmail.com

Naseem Abidi

naseem_abidi@yahoo.com

1 Jaypee Business School, JIIT, A-10, Sector-62, Noida, Uttar Pradesh 201307, India

2 School Education, Government of West Bengal, Bikash Bhavan, Salt Lake, Kolkata 700091, India 